\title{
Advantages and disadvantages of different nasal CPAP systems in newborns
}

\author{
Buettiker, V ; Hug, M I ; Baenziger, O ; Meyer, C ; Frey, B
}

\begin{abstract}
Objective: To compare three different systems of continuous positive airway pressure (CPAP): the naso-pharyngeal tube and two-prong systems in newborns, focusing on duration of CPAP, side effects and cost. Design: Randomized clinical study. Patients: Between July 2000 and September 2001 newborns were randomized to three different CPAP systems. Forty infants in two weight groups ( $>2500 \mathrm{~g}$ and 1250 2500g; 20 patients in each group) were included. Results: In the group $>2500 \mathrm{~g}$ the median duration of CPAP was 1.1days (range 0.25-14.3days). The median time on a naso-pharyngeal CPAP was 1day (range 0.25-14.3days), on Hudson prongs 1.6days (range 0.5-3.3days) and on the Infant Flow system 0.7days (range 0.3-13.6days; $\mathrm{p}>0.05$ for comparison between groups, Fisher's exact test). With naso-pharyngeal CPAP, 2 patients developed moderate nasal injuries. On Hudson, 2 patients developed moderate and three mild nasal injuries. One patient on the Infant Flow showed mild and one moderate nasal injuries. In the weight group 1250-2500g the median duration of CPAP was 1.1days (range 0.1-7.0days). The median time on the naso-pharyngeal tube was 0.9days (range 0.1-7days), on Hudson prongs 1.1days (range 0.76.6days) and on the Infant Flow system 1.3days (range 0.25-5.9days; p $>0.05$ for comparison between groups, Fisher's exact test). With a naso-pharygeal tube, one infant developed mild and one moderate nasal injuries. On Hudson prongs, two had moderate nasal injuries. On Infant Flow, one newborn showed a severe nasal injury and two mild injuries. None of the patients developed a pneumothorax. Conclusion: The naso-pharyngeal tube is an easy, safe and economical CPAP system usable with every common ventilator. For very low birth weight newborns, a prong system may have advantages
\end{abstract}

DOI: https://doi.org/10.1007/s00134-004-2267-8

Posted at the Zurich Open Repository and Archive, University of Zurich

ZORA URL: https://doi.org/10.5167/uzh-156121

Journal Article

Published Version

Originally published at:

Buettiker, V; Hug, M I; Baenziger, O; Meyer, C; Frey, B (2004). Advantages and disadvantages of different nasal CPAP systems in newborns. Intensive Care Medicine, 30(5):926-930.

DOI: https://doi.org/10.1007/s00134-004-2267-8 


\author{
V. Buettiker \\ M. I. Hug \\ O. Baenziger \\ C. Meyer \\ B. Frey
}

\section{Advantages and disadvantages of different nasal CPAP systems in newborns}

Received: 25 September 2003

Accepted: 26 February 2004

Published online: 24 March 2004

(C) Springer-Verlag 2004
V. Buettiker $(\bullet) \cdot$ M. I. Hug •

O. Baenziger $\cdot$ C. Meyer $\cdot$ B. Frey

Department of Neonatology

and Intensive Care,

University Children's Hospital,

Steinwiesstrasse 75, 8032 Zurich,

Switzerland

e-mail: vera.buettiker@kispi.unizh.ch

Tel.: +41-1-2667111

Fax: +41-1-2667168

\begin{abstract}
Objective: To compare three different systems of continuous positive airway pressure (CPAP): the naso-pharyngeal tube and two-prong systems in newborns, focusing on duration of CPAP, side effects and cost. Design: Randomized clinical study. Patients: Between July 2000 and September 2001 newborns were randomized to three different CPAP systems. Forty infants in two weight groups (>2500 g and 1250-2500 g; 20 patients in each group) were included. Results: In the group $>2500 \mathrm{~g}$ the median duration of CPAP was 1.1 days (range $0.25-14.3$ days). The median time on a naso-pharyngeal CPAP was 1 day (range 0.2514.3 days), on Hudson prongs 1.6 days (range $0.5-3.3$ days) and on the Infant Flow system 0.7 days (range 0.3-13.6 days; $p>0.05$ for comparison between groups, Fisher's exact test). With naso-pharyngeal CPAP, 2 patients developed moderate nasal injuries. On Hudson, 2 patients developed moderate and three mild nasal injuries. One patient on the Infant Flow showed mild and one
\end{abstract}

moderate nasal injuries. In the weight group 1250-2500 g the median duration of CPAP was 1.1 days (range 0.1-7.0 days). The median time on the naso-pharyngeal tube was 0.9 days (range $0.1-7$ days), on Hudson prongs 1.1 days (range 0.76.6 days) and on the Infant Flow system 1.3 days (range $0.25-$ 5.9 days; $p>0.05$ for comparison between groups, Fisher's exact test). With a naso-pharygeal tube, one infant developed mild and one moderate nasal injuries. On Hudson prongs, two had moderate nasal injuries. On Infant Flow, one newborn showed a severe nasal injury and two mild injuries. None of the patients developed a pneumothorax. Conclusion: The naso-pharyngeal tube is an easy, safe and economical CPAP system usable with every common ventilator. For very low birth weight newborns, a prong system may have advantages.

Keywords Continuous positive airway pressure - Nasal prongs . Infants $\cdot$ Naso-pharyngeal tube

\section{Introduction}

Since the implementation of continuous positive airway pressure (CPAP) in 1971 in the neonatal wards [1], noninvasive ventilation for the treatment of respiratory distress syndrome of different aetiologies has become increasingly more important. In term and preterm infants, CPAP helps to stabilize the chest wall and leads to an increase of tidal volume during inspiration. Lung volume can be preserved by shortening the expiratory time and preventing the lung from emptying completely [2]. These are only two of the many effects of CPAP support in newborns. Various systems are available presently: nasopharyngeal tube, different prong systems and mask CPAP. Side effects are well known and include tube or prong obstruction, air leaks and gastric distention [3], but 
it is not described how often we see side effects in neonatal patients. Nasal irritation, damage to the septal mucosa or skin damage, necrosis from the fixing devices or difficulties with the fixation are other complications of CPAP [4, 7]. Robertson et al. [4] report a proportion of $20 \%$ with nasal irritations in patients on flow driver. The aim of the present study was to review the different systems used in our intensive care unit over the past 4 years. We compared two different prong systems and the conventional naso-pharyngeal tube with regard to length of treatment, appropriateness for different weight classes, side effects and costs.

\section{Patients and methods}

Our intensive care unit is a tertiary centre for newborns. Between July 2000 and September 2001 all newborn infants ( $<28$ days) who met the entry criteria for the study were randomized to three different CPAP systems. The study was approved by the local research ethics committee. Inspired by the study by Robertson et al. [4] who described a complication rate of $20 \%$ in very low birthweight newborns on a flow driver system, we proposed that the complication rate with nasal-pharyngeal tube may be lower. In all, 40 infants in two weight groups (1250-2500 g, >2500 g; 20 patients in each group) were included in the study. In each group 8 patients were randomized to a naso-pharyngeal tube and 6 each to one of the two-prong systems. The entry criteria were clinical signs of respiratory distress (RDS) with need of oxygen above $40 \%$, and $\mathrm{pCO}_{2}$ above $7 \mathrm{kPa}$ in an arterial blood gas or $7.5 \mathrm{kPa}$ in a capillary blood gas. The diagnosis of RDS was based on at least two of the four classic symptoms: cyanosis; tachypnoea; intercostal retractions; nasal flaring; and grunting. We included newborns who were primarily intubated and needed CPAP after extubation. Patients were extubated when they were able to hold a pulsoximeter oxygen saturation above $85 \%$ with an inspired oxygen fraction less than $40 \%$ and an inspiratory pressure $\leq 18 \mathrm{cmH}_{2} \mathrm{O}$ and PEEP of $4 \mathrm{cmH}_{2} \mathrm{O}$. Criteria for the initiation of CPAP in these patients were the same as described above. Excluded were infants with congenital heart disease, necrotizing enterocolitis or upper airway abnormalities. Each infant could be randomized only once.

We studied the three CPAP systems routinely in use in our intensive care unit and according to the instruction of the manufacturer. The nursing staff was introduced to the systems by the manufacturer and had been using all the systems for several years. The correct position of the systems was checked every shift by the nursing staff. The first system was the naso-pharyngeal tube (Vygon, Cirencester, UK) in sizes of 2.0-, 2.5-, 3.0-, and 3.5-mm inner diameter. We used a tube as wide as possible to reduce the resistance to airflow but not so big that the nostril was filled out completely. The tube was connected to two different ventilators, either to a Dräger Medical International Babylog 1 or Evita 4 with a heated humidifier and oxygen analyser. The price for a tube and connecting set was 18.90 Euro. The tube position was the distance between ear and nose minus $1.5 \mathrm{~cm}$. We changed the tube every $24 \mathrm{~h}$. The second CPAP system was the Hudson prongs (Hudson Respiratory Care, Temecula) connected to a Babylog 1 or Evita 4 (price for prongs and connecting set=39.50 Euro). The third was the Infant Flow system (Hamilton Medical, Reno, NV; manufactured by EME, Ltd, Brighton, UK) either connected to a Babylog 1 or the Aladin (price 98.30 and 95.90 Euro, respectively). Both systems were fixed with the cap provided according to the manuals for each system. All nurses were familiar with the different systems. The PEEP we routinely use is $3-5 \mathrm{cmH}_{2} \mathrm{O}$. The nasal injuries were graduated into three stages: mild; moderate; and severe. Mild was defined as a reddening around the nasal ostium. A moderate injury was defined as bleeding either at the septum or nasal ostium. A severe nasal injury was necrosis either on the septum or nasal ostium. All infants were followed up by the same neonatologist (V.B.) or the same nurse (C.M.) who is experienced with CPAP.

Data were collected for diagnosis, gestational age, age when randomized, actual weight, duration of CPAP, level of PEEP, blood gas at the time of randomization, need for sedation, CPAP complication (blocked tube, air leak), nasal irritation, problems of CPAP fixation or patient positioning while on CPAP. Furthermore, we recorded whether the patient was already on CPAP while being transported to our unit. Patients were randomized as soon as we received the order to transfer a baby to our hospital.

The CPAP was stopped when there was either increasing respiratory insufficiency with a need for intubation or an $\mathrm{FiO}_{2}$ of less than $30 \%$ for more than $4 \mathrm{~h}$ with normal arterial blood gas $(\mathrm{ph} \geq 7.3$, $\mathrm{pCO}_{2} \leq 7 \mathrm{kPa}$, pulse oximeter oxygen saturation $\left.>85 \%\right)$.

Data are given as medians (range in parentheses). Comparison of proportions is done by the Fisher's exact test and comparison of unpaired continuous variables by the Mann-Whitney U test. A $p$ value of $<0.05$ was considered as statistically significant.

\section{Results}

In the $>2500 \mathrm{~g}$ group, the median weight was $3245 \mathrm{~g}$ (range 2650-4820 g). Most of the patients required CPAP for the treatment of transient tachypnoea of the newborn (Table 1). The median duration of CPAP was 1.1 days (range $0.25-14.3$ days). Of all patients, $75 \%$ in this group were on CPAP for less than 2 days (Fig. 1). The median time on a naso-pharyngeal CPAP was 1 day (range 0.25 14.3 days), on Hudson prongs 1.6 days (range 0.53.3 days) and on the Infant Flow system 0.7 days (range 0.3-13.6 days; $p>0.05$ for comparison between groups, Fisher's exact test). There were two infants with a duration $>5$ days; one had a neuromuscular disease and the other Jeune syndrome. Of the patients on naso-pharyngeal CPAP, two developed moderate injuries. On the Hudson system, 2 patients showed moderate and three mild injuries. In the group treated with the Infant Flow system, 1 patient showed mild and one moderate injuries. None of the patients $>2500 \mathrm{~g}$ had necrosis (Table 1). Three patients required CPAP after intubation, but none of them showed nasal injuries. In 18 patients CPAP was ceased due to improvement of their respiratory function. One patient required intubation and 1 infant developed severe

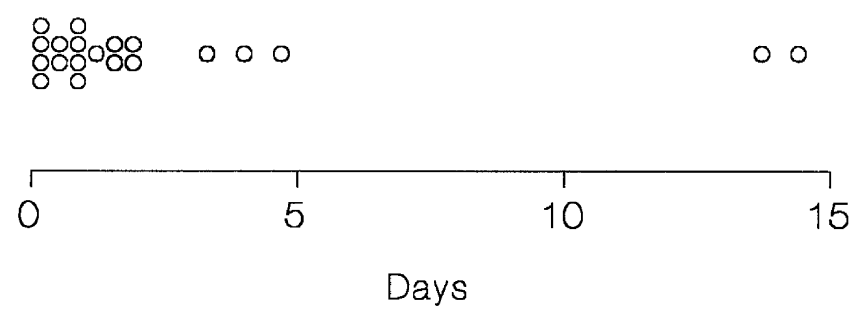

Fig. 1 Duration of continuous positive airway pressure (CPAP) for newborns $>2500 \mathrm{~g}$. Most of the patients needed CPAP for $<2$ days 
Table 1 Demographic data and diagnosis in the weight group $>2500 \mathrm{~g}$. HMD hyaline membrane disease, TT transient tachypnea of the newborn. $C P A P$ continuous positive airway pressure

\begin{tabular}{|c|c|c|c|c|c|}
\hline Diagnosis & $\begin{array}{l}\text { Weight } \\
(\mathrm{g})\end{array}$ & $\begin{array}{l}\text { Duration of CPAP } \\
\text { (days) }\end{array}$ & $\begin{array}{l}\text { Gestational age } \\
\text { (weeks) }\end{array}$ & Nasal injury & CPAP system \\
\hline Bilateral pneumothorax & 3440 & 1.29 & 38.7 & No & Naso-pharyngeal \\
\hline TT & 2650 & 0.73 & 37.9 & Mild & Hudson \\
\hline RSV & 4820 & 0.5 & 40.4 & Mild & Hudson \\
\hline Jeune syndrome & 3320 & 13.6 & 38.7 & Mild & Infant Flow \\
\hline HMD & 2840 & 1.4 & 36 & Mild & Hudson \\
\hline TT & 3040 & 4.8 & 37.4 & Mild & Naso-pharyngeal \\
\hline TT & 3625 & 1.9 & 37.1 & No & Infant Flow \\
\hline Cystic fibrosis & 2670 & 3.3 & 33.6 & Moderate & Hudson \\
\hline TT & 3360 & 0.8 & 36 & No & Naso-pharyngeal \\
\hline TT & 4030 & 0.7 & 39.1 & No & Naso-pharyngeal \\
\hline TT & 3140 & 0.3 & 40.7 & No & Infant Flow \\
\hline Sepsis & 3070 & 2 & 37.4 & Mild & Naso-pharyngeal \\
\hline TT & 2900 & 0.9 & 35.9 & No & Infant Flow \\
\hline Right-side pneumothorax & 3440 & 0.3 & 35.7 & No & Infant Flow \\
\hline Neuromuscular disease & 3170 & 14.3 & 38.4 & No & Naso-pharyngeal \\
\hline Oesophageal atresia & 4090 & 1.7 & 40.7 & No & Hudson \\
\hline TT & 3640 & 4 & 38.1 & Moderate & Hudson \\
\hline TT & 2830 & 0.5 & 34 & Moderate & Infant Flow \\
\hline TT & 3140 & 0.25 & 37.1 & No & Naso-pharyngeal \\
\hline Sepsis & 3520 & 0.3 & 40.1 & No & Naso-pharyngeal \\
\hline
\end{tabular}

Table 2 Demographic data and diagnosis in the weight group 1250-2500 g. NEC necrotizing enterocolitis

\begin{tabular}{|c|c|c|c|c|c|}
\hline Diagnosis & $\begin{array}{l}\text { Weight } \\
(\mathrm{g})\end{array}$ & $\begin{array}{l}\text { Duration of CPAP } \\
\text { (days) }\end{array}$ & $\begin{array}{l}\text { Gestational age } \\
\text { (weeks) }\end{array}$ & Nasal injury & CPAP system \\
\hline HMD & 1760 & 1 & 32.1 & No & Infant Flow \\
\hline HMD & 2400 & 0.1 & 34.3 & No & Naso-pharyngeal \\
\hline Steiner's myopathia & 1900 & 0.25 & 35.6 & No & Infant Flow \\
\hline HMD & 2160 & 0.9 & 36.1 & No & Naso-pharyngeal \\
\hline HMD & 1310 & 0.7 & 29.6 & No & Hudson \\
\hline HMD & 2470 & 1.4 & 33.6 & Moderate & Hudson \\
\hline HMD & 1750 & 1.2 & 30.7 & Severe & Infant Flow \\
\hline HMD & 1310 & 7 & 29 & No & Naso-pharyngeal \\
\hline HMD & 1790 & 2.1 & 31.4 & No & Hudson \\
\hline HMD & 1480 & 5.9 & 29.6 & Moderate & Infant Flow \\
\hline RSV & 1790 & 1.7 & 30.7 & Moderate & Naso-pharyngeal \\
\hline HMD & 1400 & 6.6 & 30.4 & Moderate & Hudson \\
\hline HMD & 1970 & 1.8 & 33.5 & No & Naso-pharyngeal \\
\hline
\end{tabular}

sepsis and went on to respiratory failure. None of the patients developed pneumothorax on CPAP. There was no significant difference in the first blood gas before CPAP between the different groups. One problem noticed by the nursing staff was the fixation of the prongs system. The problem occurred in 4 patients on the Hudson system and in one on Infant Flow. In two instances the naso-pharyngeal tube became blocked during the first $24 \mathrm{~h}$ and needed to be changed earlier than anticipated. We rou- tinely changed the tube every $24 \mathrm{~h}$ and the gas was humidified at $37.5^{\circ}$.

Of the 20 patients in the $>2500 \mathrm{~g}$ group, seven were transferred to the hospital on CPAP without any problem. All three systems were used for transport.

In the group of patients weighing 1250-2500 g, the median weight was $1790 \mathrm{~g}$ (range 1310-2470 g). The diagnosis which led most often to the clinical sign of respiratory distress and the need for CPAP was hyaline membrane disease (Table 2). Seven of the babies required 


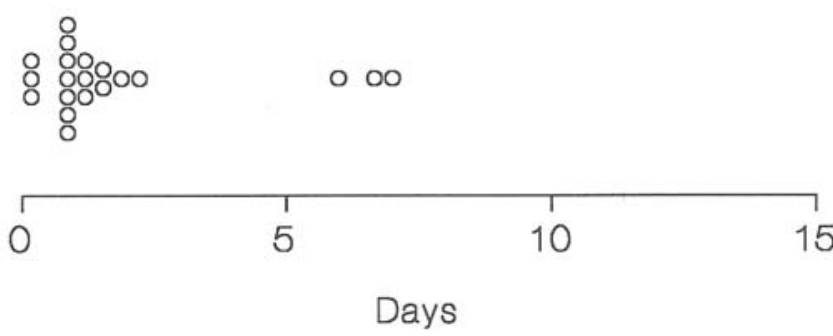

Fig. 2 Duration of CPAP for newborns weighing 1250-2500 g. Most of the patients were on CPAP for $<2$ days

CPAP after mechanical ventilation for increasing need of oxygen and/or increasing $\mathrm{CO}_{2}$ after extubation. The median duration of CPAP was 1.1 days (range 0.1-7.0 days). Of all babies in this group, $80 \%$ had a CPAP time of $<2$ days (Fig. 2). The median time on the naso-pharyngeal tube was 0.9 days (range 0.1-7 days), on Hudson prongs 1.1 days (range 0.7-6.6 days) and on the Infant Flow system 1.3 days (range 0.25-5.9 days; $p>0.05$ for comparison between groups, Fisher's exact test). In the group of patients treated with a naso-pharygeal tube one baby developed mild nasal injuries and one moderate injuries. None of them had severe injuries. On the Hudson prongs, 2 infants had moderate injuries. With the Infant Flow system, one newborn infant showed severe nasal injury and two mild injuries (Table 2). Four patients in this weight group needed intubation. Two of them had a neuromuscular disease, the other two had HMD and suffered respiratory failure. The naso-pharyngeal tubes were occluded by secretions in 2 patients and needed to be changed promptly. One patient had severe apnoea when the naso-pharyngeal tube was inserted and needed a few seconds of bag and mask ventilation.

In both weight groups 7 of $12(58 \%)$ patients on Hudson prongs, 5 of $12(41 \%)$ patients on Infant Flow and 4 of $16(25 \%)$ patients on naso-pharyngeal tube showed nasal injuries $(p>0.05$ for comparison between groups, Fisher's exact test). None of the patients in whom CPAP was ceased needed to go back to CPAP support. Similar problems with fixation for both prong systems were described by the nursing staff. None of the babies required sedation during CPAP.

\section{Discussion}

Continuous positive airway pressure is a well-established form of ventilatory support in all weight groups of newborns. Different studies have tried to compare the advantages of one or the other system with a focus on reintubation rate and time on CPAP [5, 6]. This study focused on the side effects of three different CPAP systems in newborn infants with weights of either $1250-2500 \mathrm{~g}$ or above $2500 \mathrm{~g}$. These are the patient groups usually treated in a neonatal tertiary ward with predominantly outborn patients. The costs in our medical system get increasingly higher, but we still have to do the best for our patients. The naso-pharyngeal tube is an established and cheap method of delivering CPAP to neonates. In the very low birth weight group, Davis et al. had a lower failure rate with a binasal prong system compared to naso-pharyngeal CPAP [6]. Stefanescu et al. showed in a prospective randomized study no advantage regarding effectiveness of Infant Flow system compared with naso-pharyngeal tube in extremely low birth weight infants [9]. Lung function studies, such as the study by Courtney et al., showed a higher lung recruitment when using a variable flow device but no difference between nasal cannula and CPAP prongs [10]. In our study we could not show any significant difference between the three systems with regard to the respiratory failure rate; however, the Hudson system showed more injuries to the nose ( 7 patients) than the other two systems in both weight groups but without statistical significance. This may be due to the flexion of the Hudson prongs. The Infant Flow system is made of a softer material. In both prong systems, the nursing staff described problems with fixation and generation of PEEP was inadequate when the babies were moving and the prongs shifting. For the nursing staff, it was sometimes difficult to fix the prong systems properly, especially in the bigger infants. Compared with these difficulties, the naso-pharyngeal tube was easy to fix, but the tape did damage the skin, especially in the group $<2500 \mathrm{~g}$. There was a problem with the naso-pharyngeal tubes in small babies due to obstruction by thick secretion and the tube needed to be changed immediately in two instances. In babies $>2500 \mathrm{~g}$ we did not have this problem.

None of the patients showed pneumothorax as a side effect of the treatment with CPAP. Regarding the duration of CPAP, there was no significant difference between treatment groups. The time on CPAP seemed to be dependent on the illness of the patient. The two patients with 13.6 and 14.3 days on CPAP both had a neuromuscular disease. Most of the patients needed CPAP for $<2$ days. In the lower weight group, 9 patients had been intubated before CPAP, compared with three in the weight class $>2500 \mathrm{~g}$. In the weight groups of this study no system was superior to the others, but the price for each system differed substantially. The reason for the short CPAP times in our patients may be their relatively high birth weight $(>1250 \mathrm{~g})$. A major limitation of our study is the small sample size. We anticipated a higher number of patients, but the significant number of nasal injuries led to the decision to stop the study. We developed a treatment protocol: in our institution patients with a weight under $2500 \mathrm{~g}$ have CPAP on Infant Flow prongs. Patients with a weight over $2500 \mathrm{~g}$ have a naso-pharyngeal tube. 


\section{Conclusion}

In conclusion, naso-pharyngeal tubes are an easy, safe and economical CPAP system usable with every common ventilator. There might be advantages for the prong systems in babies with very low birth weight, because naso- pharyngeal tubes become blocked more easily and the resistance is higher [8]; however, the prong systems are much more expensive and this has to be balanced against their advantages in view of the fact that the median CPAP time is short in newborns $>1250 \mathrm{~g}$.

\section{References}

1. Gregory GA, Kitterman JA, Phibbs RH, Tooley WH, Hamilton WK (1971)

Treatment of the idiopathic respiratory distress syndrome with continuous positive airway pressure. N Engl J Med 284:1330-1340

2. Martin RJ, Okken A, Katona PG, Klaus MH (1978) Effect of lung volume on expiratory time in the newborn infant. J Appl Physiol Respir Environ Exercise Physiol 45:18-23

3. Morley C (1999) Continuous distending pressure. Arch Dis Child Fetal Neonatal Ed 81:F152-F56

4. Robertson NJ, McCarthy LS, Hamilton PA, Moss ALH (1996) Nasal deformities resulting from flow driver continuous positive airway pressure. Arch Dis Child Fetal Neonatal Ed 75:F209-F212
5. Mazzella M, Bellini C, Calevo MG, Campone F, Massocco D et al. (2001) A randomised control study comparing the Infant Flow Driver with nasal continuous positive airway pressure in preterm infants. Arch Dis Child Fetal Neonatal Ed 85:F86-F90

6. Davis P, Davies M, Faber M (2001) A randomised controlled trial of two methods of delivering nasal continuous positive airway pressure after extubation to infants weighing less than 1000 g: binasal (Hudson) versus single nasal prongs. Arch Dis Child Fetal Neonatal Ed 85:F82-F85

7. Millet V, Lacroze V, Bartoli JM, Unal D (1997) Necrosis of the nasal columella secondary to nasal continuous positive airway pressure. Arch Pediatr $5: 485$
8. Paoli AG de, Morley CJ, Davis PG, Lau R, Hingeley E (2002) In vitro comparison of nasal continous positive airway pressure devices for neonates. Arch dis Child Fetal Neonatal Ed 86:F42-F45

9. Stefanescu B, Murphy P, Hansell B, Fuloria M, Morgan T, Aschner J (2003) A randomized, controlled trial comparing two different continuous positive airway pressure systems for the successful extubation of extremely low birth weight infants. Pediatrics 112:1031-1038

10. Courtney S, Pyon K, Saslow J, Arnold G, Pandit P, Habib R (2001) Lung recruitment and breathing pattern during variable versus continuous flow airway pressure in premature infants: an evaluation of three devices. Pediatrics 107:304-308 